Lamont Geological Observatory

Palisades, New York

\title{
Columbia Antuersity
}

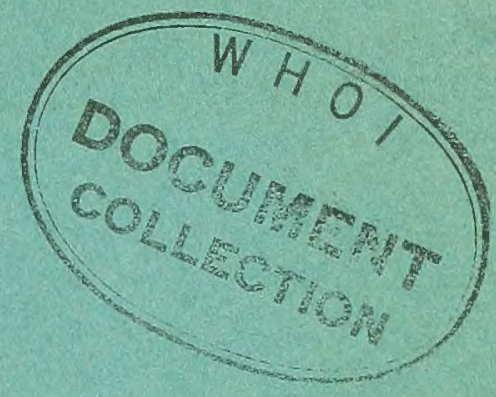

\section{Reduction of Deep Sea Refraction Data}

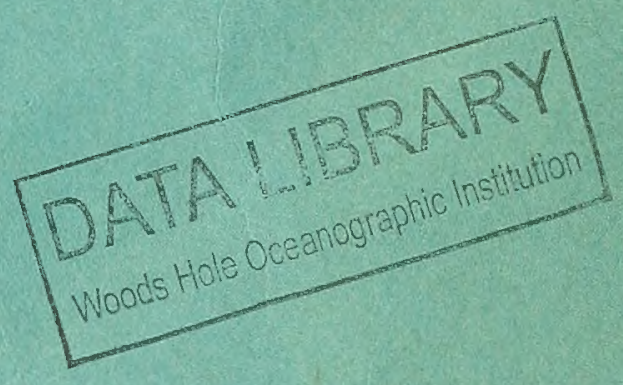

Technical Report No. 1

(Contract NO bsr 43355)

QE

39

.043

1951 


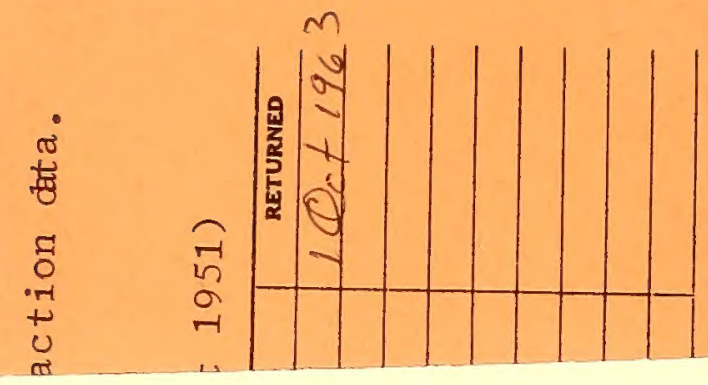




\title{
Lamont Geological Observatory \\ (Columbia University) \\ Palisades, New York
}

\author{
Reduction of Deep Sea Refraction Data \\ Technical Report No. I
}

by

Charles B. Officer

Paul C. Wuens chel

The research reported in this document has been made possible through support and sponsonship extended by the U. S. Navy, Bureau of Ships under Contract NObsr 43355. It is published for technical information only and does not reprssent recommendations or conclusions of the sponsoring agency.

August 1951 
Table of Contents

Page

I. Introduction 1

II. Shot Instant Correction 2

III. Sinking Rates of Explosive Charges 4

IV. Reduction to Surface of Reference 5

V. Topographic Correction 7

VI. Curvod Ray Paths 7

VII. Sound Velocities in the Ocean 8

VIII. Check Plots 9

IX. $R_{I}-D$ versus $R_{I}$ Graphs 10

X. Check List of Data Necessary for 11

Complete Reduction 



\section{List of Figures}

1 - Shot and Shooting Ship

2 - Bottom and Surface-bottom Reflections

3 - Sinking Rate Graph for $\frac{1}{2}$ - 1 \# Charges of $\frac{1}{2}$ \# Blocks

4 - Sinking Rate Graph for $3-5$ \# Charges of $\frac{1}{2}$ \# Blocks

5 - Sinkine Rate Graph for 8 - 10 \# Charges of $\frac{1}{2}$ \# Blocks

6 - Sinking Rate Graph for 18 - 25 \# Charges of $\frac{1}{2}$ \# Blocks

7 - Sinking Rate Graph for 50 \# Charges of $\frac{1}{2}$ \# Blocks

8 - Sinking Rate Graph for 25 \# Canadian Depth Charges

9 - Sinking Rate Graph for Mk 42T 100 \# Aerial Bombs

10 - Sinking Rate Graph for Mk 30100 \# Aerial Eombs

11 - Sinking Rate Graph for Mk VI 300 \# Depth Charges

12 - Sinking Rate Graph for Mk 54350 \# Aerial Depth Charges

13 - Ray path for $R_{1}$

14 - Ray paths for $D, R_{l}$, and $G$

15 - Graph for Correction of $R_{1}$ to Reference Surface

16 - Graph for Correction of $R_{2}$ to Reference Surface

17 - Graph for Correction of $R_{3}$ to Reference Surface

18 - Graph for Correction of $G$ to Reference Surface

19 - Graph of Topoeraphic Corrections

20 - Graph of $R_{I}$ - D versus $R_{I}$ 
Reduction of Deep Sea Refraction Data

Charles B. Officer and Paul C. Wuenschel

\section{Introduction}

During the summer of 1950 an extensive two ship deep sea refraction operation was made on Atlantis 164 and Caryn 17 cruises. A total of seventy refraction stations were made on tracks from Bermuda to Charleston, Norfolk to Bermuda, Bermuda to the Nares Deep, Bermuda to Halifax, and Halifax to Woods Hole. Again during the spring of 1951 the opportunity arose to make another two ship refraction operation on Atlantis 172 and Caryn 22 cruises. Thirtythree profiles were made covering the Caribbean, the Puerto Rico Trough, and a track from Puerto Rico to Bermada to Woods Hole.

It has been necessary to make several corrections and reductions to the raw data in order to obtain the final values for the travel time plots. The method of reduction of the deep sea refraction data is not found in any of the standard ceophysical texts, and that used in shallow water seismic work is not applicable. It has been necessary to devise new methods as the occasion arose. These methods of reduction are, in general, quite simple; but it has been thought advantageous to present them in this form for the benefit of and use in future investigations. Further it is hoped that this report results in a uniform method of 
reducing deep sea refraction data. The several graphs that have been found helpful in carrying out the reductions have al so been included in such a manner that they may be used directly from the report.

\section{Shot Instant Correction}

In a two ship refraction operation one ship, say the Atlantis, heaves to and lowers her hydrophones preparatory to receiving. The Caryn then proceeds on course shooting the necessary shots to make the profile. After completine the shooting, the Caryn heaves to and prepares to receive, as the Atlantis gets underway on course toward the Caryn, firing shots to complete the reverse profile.

The shot instant is picked up on the shootine ship and sent over the air to the receiving ship where it is recorded on the refraction record. Simultaneously, a shot record is made on the shootine ship. Several identifiable buzzes and signals are sent over the air after the shot and recorded on both the shot and refraction record in order to allow correlation of the two records and location of the shot instant on the refraction record when, due to poor radio contact or other causes, the shot instant is not recorded on the refraction record. Besides allowing this correlation the shot record is useful in determinine the depth of the shot.

After locating the shot instant on the refraction record either by direct reading or by correlation with the 
shot record, It is necessary to make a correction for the time it took the shot instant to travel from the shot point to the shooting ship (see Figure 1). In order to do this It is necessary to know the depth of the shot and the distance that the ship has traveled from the time the shot was thrown over the side to the time it detonated.

The distance that the ship has moved is obtained by multiplying the ship's speed by the time over the side. The timo over the side is the interval from the instant the charge is thrown over the side to the instant of detonation. The depth of shot is read directly from the shot record. It
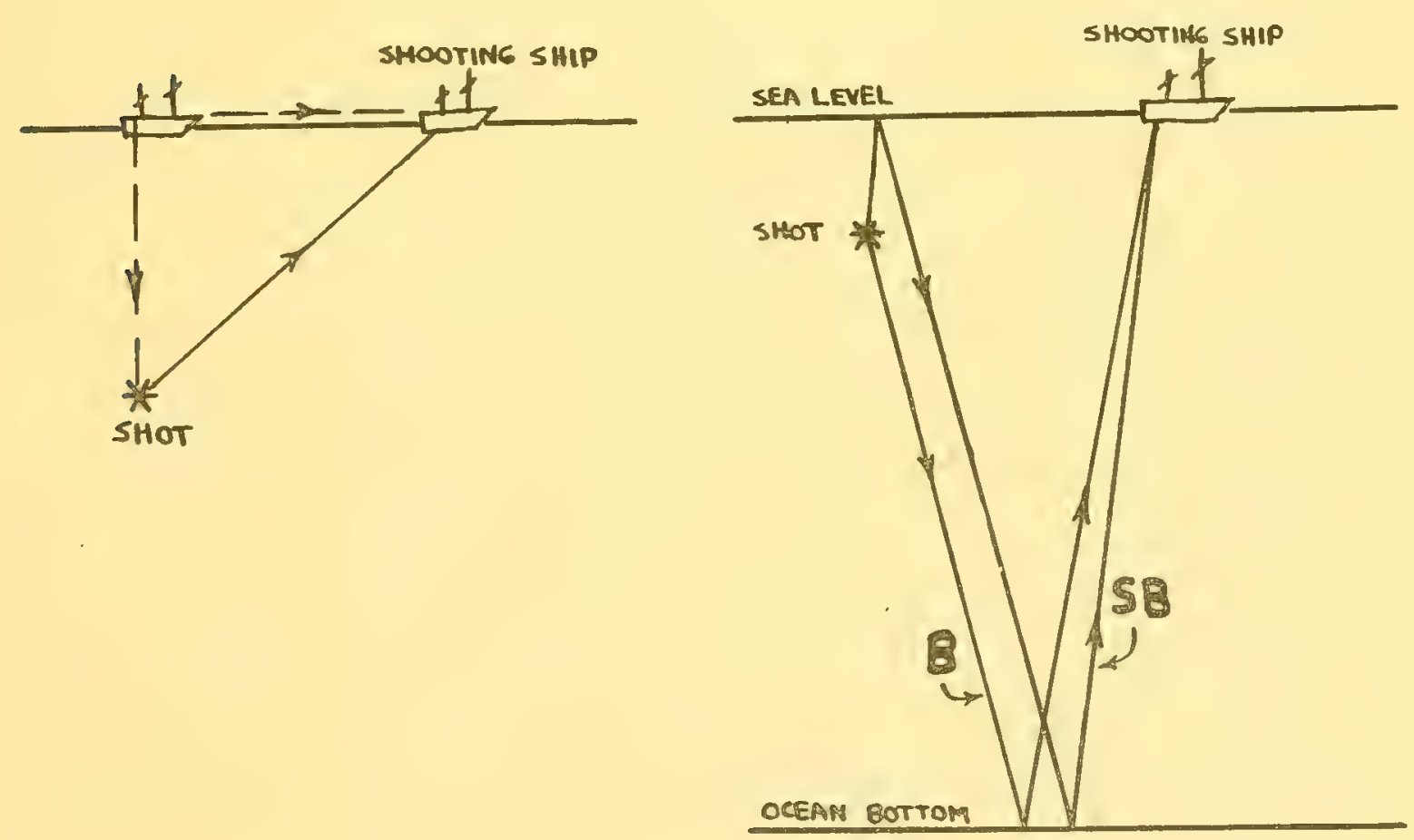

Fig. I Shot and Shooting Fig. $2 \begin{aligned} & \text { Bottom and Surface-bottom } \\ & \text { Reflections }\end{aligned}$ 
is equal to half the time difference between the bottom and the surfaco-bottom reflections for depths of water greater than 1000 fathoms (see Figure 2). It is then an easy matter to calculate, knowing the velocity of sound in the water from the bathythermograph observations, the time it took the shot instant to travel from the shot point to the shooting

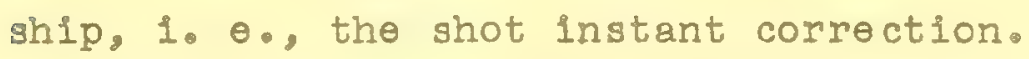

\section{Sinking Rates of Explosive Charges}

Unless the shot record is recorded photographically, It is not possible to read the bottom-surface bottom reflection interval with consistency; and even on some of the photographic records it is not possible to read this interval due either to blocking of the amplifier or excessive noise level. For these shots it is necessary to use the data from those shots on which this interval could be read. This is most easily done by referring to the sinking rate graphs (see Figures 3 - 12). These are plots of twice the depth of the explosion, 1. $\theta$., the bottom-surface bottom interval, versus the time over the side. Knowing the time over the side the depth of the explosion can then be read off the graphs. The scatter of the plotted points about the line that is drawn is \pm .01 second for the depth of the explosion. It can safely be assumed that any readings taken from these graphs will be accurate to that figure, in the range of the observed points.

All the charces that were used in plotting the se points were fired by safety fuse. The chares consisting of 
$\frac{1}{2}$ pound demolition blocks were prepared by taping or tying the blocks together. Sometimes $3 \frac{1}{2}$ pound demolition blocks were used also. The 50 pound charges of demolition blocks were prepared by replacine the top and bottom of the 50 pound boxes by slats and removing all the wax paper. The Mn $42 \mathrm{~T}$ charges were fired without the associated tail assembly, and the Mk 30 charges were fired with the tail assembly. The luk 54 charges were fired in thoir carrying cases.

IV. Reduction to Surface of Reference

It is usually desirable to reduce the travel time data to a surface of reference from which to measure seismic depths. In the case of deep sea refraction profiles sea level is chosen as the most convenient surface of reference. The refraction, reflection, and direct wave travel times are corrected to bring them to this surface of reference. The correction to the first reflection is the time it would take sound in vater to travel from $A$ to $B$ plus the time from $C$ to $D$ (see Figure 13). This is obta: ned by multiplying the depth of the shot plus the depth of the hydrophone, expressed in seconds, by $\cos \theta$, where $\theta$ is the angle of incidence of the reflected wave on the bottom. The correction for the second and third reflections is obtained in a similar manner. The correction for the refracted waves is equal to the product of the sum of these depths by the cosine of the angle (W) whose sine is the ratio of the averase water velocity ( $\left(\bar{c}_{v}\right)$ to the velocity in the refracted layer $\left(c_{n}\right)$. The correction for the 
direct wave is negligable for most of the shots. (The ray paths for these various arrivals are shown in Figure 14.)
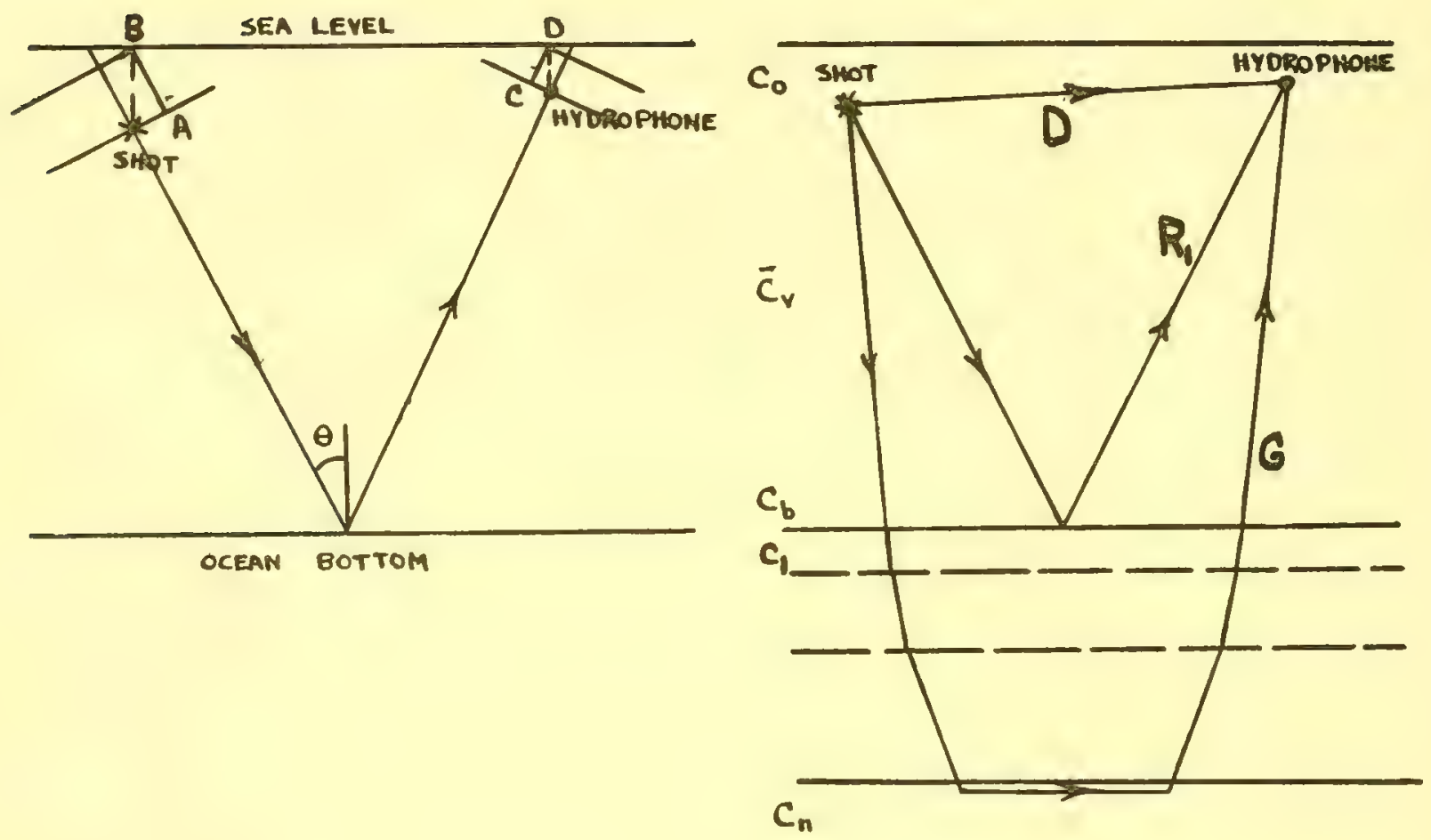

FiE. 13 Ray path for $R_{1}$ FiE. 14 Ray paths for $D, R_{1}$, and $G$ Ficures $15-17$ are graphs of $\cos \theta$ verus direct wave travel time, 1. e., rance, for the first, second, and third reflections. The factor that is needed to multiply the sum of the depths of the shot and hydrophone can be read directly off this graph for the particular range involved. Figure 18 is a Eraph of $\cos \alpha$ versus the ratio $c_{n} / \bar{q}$. From this graph the same factor can be read off for the refraction 
arrivals. For all basement velocities that are obtained in deep sea refraction work, 1. e., $c_{n} / \overline{c F}$ Ereater than 4.0, this factor may be taken equal to unity.

V. Topoeraphic Correction

Areas of moderate to small topography were chosen for most of the deep sea refraction profiles; but before any calculations of basement velocity or depth can be made, It is necessary to remove the small effects of the 1rregularities in the bottom topoeraphy on the refraction travel times. A mean depth of water is chosen, and corrections are made plus and minus about this depth for the travel times of refraction arrivals. Difficulty arises in choosing what material the bottom topography takes place, whether it represents directly topography in the sediments or is a representation of the basement topography. The choice that is made depends on the type of typography and structure involved.

Figure 19 is a set of Eraphs of the corrections to be applied to the Eround arrivals versus the difference in elevation of the bottom topography from the mean for various velocity contrasts between the material forming the bottom topography and the ocean.

VI. Curved Ray Paths

The time intercept for a refraction line in the simplest case of a single rofracting lajer is given by the approximate formula,

$$
I=\frac{2 H}{c_{1} \bar{c}_{v}} \sqrt{c_{1}^{2}-\left(\bar{c}_{v}\right)^{2}}
$$


where $\bar{c}_{v}$ is the "time averace" of the sound velocity in water taken from sea level to the bottom. It is defined by the relation,

$$
\bar{c}_{v}=\frac{H}{\int_{0}^{H} \frac{d h}{C_{v}}}
$$

and is that velocity which when multiplied by the vertical reflection time will give the true depth of water. Equation I is approximate because it takes an average vertical velocity for the water. It does not give the exact expression for the change in the intercept ray path cue to the velocity structure in the water nor the change in time over this path. Calculations by Tolstoy and separately by Worzel and Officer show that the approximate formula is valid to 0.002 seconds for refraction velccities Ereater than 20,000 feet per second and is valid to 0.01 for velocities greater than 5600 feet per second at a depth of water of 2700 fathoms. Thus, it is concluded that the approximate formula can be used with neglicable error for any deep sea basement calculations.

\section{Sound Velocities in the Ocean}

For refraction calculations it is necessary to know surface sound velocity in water for the determination of range from the firect wave and the average vertical velocity for the determination of refraction depths. The surface sound velocity is determined from the bathythermographic observations taken along the shooting track and the surface 
salinity, quoted in various oceanographic reports for the particular area and season involved. Sound velocity is not critically dependent on the variations observed in salinity so that with the bathythermographic observations that have been taken the surface sound velocity can usually be quoted to \pm 2 feet per second. The average vertical velocity is obtained from "Tables of the Velocity of Sound in Pure Water and Sea Water," published by the Hydrographic Department, Admiralty, Iondon (1939). A check on this value is obtained from the $R^{2}$ versus $D^{2}$ plots. These two values usually agree to \pm 10 feet per second, but for the sake of uniformity the British Admiralty Table value is used in all refraction calculations.

VIII. Check Plots

In order to insure confidence in the data used in the travel time Eraphs, two check fraphs are made. These are the $R^{2}$ versus $D^{2}$ and the navigation plots. $R_{1}^{2}, R_{2}^{2}, R_{3}^{2}, \cdots \cdots p l o t t e d$ against $D^{2}$ will produce stralght lines except for changes in depth or slope of the bottom. These graphs will then bring out any obvious errors that have been made in $R$ or in $D$. The slope of this Iine is the square of the ratio $c_{0} / \bar{c}_{\mathrm{v}}$, which gives a check on the value obtained from the Eritish Admiralty Tables for $\bar{c}_{\mathrm{v}}$. The value for $\bar{c}_{\mathrm{v}}$ can not be read from this plot to better than \pm 10 feet per second. The navigation plot is a graph of time of day that 
the charge was thrown over the side versus the direct wave travel time. This will also plot as stralght line depending on the constancy of the ship's speed and course. Besides checking the value of $D$, this Eraph is useful in giving the velocity of the shooting ship when there is no pit log on that ship. Further, the navigation plot in conjunction with the ship's log gives the range of the reverse point when no shot was fired at this station.

IX. $R_{I}-D$ Versus $R_{I}$ Graphs

Depending on the thickness of the isothermal surface water layer, the direct wave is recorded from six to forty miles. On those refraction records for which there is no D present, $R_{1}$ is used to determine the range. In the laboratory the $R_{1}^{2}$ versus $D^{2}$ plots are used to find the range at short distances (less than 40 miles), and curved ray path calculations are used for the longer shots. However, at sea it is desirable to have a quicker method for the rough travel time plots. For this purpose the $R_{1}-D$ versus $R_{I}$ curves are included (see Figure 20). Knowing the value of $R_{I}$ and the depth of the water, the expected time interval between $R_{1}$ and $D$ can te read off the Eraph. These curves are not accurate for the longer shots because the velocity structure in the water becomes important, and the simple stralght line, average velocity calculations are in error. These curves are plotted from the equation,

$$
R_{1}-D=\sqrt{\frac{C_{0}^{2}}{\left(\bar{C}_{V}\right)^{2}} D^{2}+4 \frac{H^{2}}{\left(\bar{c}_{V}\right)^{2}}}-D \text {. }
$$




\section{Check Iist of Data Necessary for}

Complete Reduction

In Eeneral -

1. Ship's navigation.

2. Ship's log.

3. Miscellaneous data not appearing in ship's log such as distance and azimuth when shooting ship is abeam at beginning and end of reversed proflle, time shooting ship is abeam, and propeller revolutions at time of each shot when no pit log or taffrail log is avallable.

4. Lathythermograph observations.

For each shot -

1. Charge slze and fuse length.

2. Time of day the charce was thrown over the side.

3. Amount of time charge was over the side before detonation.

4. Depth of water under shot. (Also indicate shot on fathometer tape.)

5. Pit log speed and mileage. 


\section{Symbols used}

$c_{0}=$ surface sound velocity in the ocean

$\bar{c}_{\mathrm{V}}=$ average vertical velocity of sound in the ocean

$c_{b}=$ sound velocity at the bottom of the ocean

$c_{1}=$ velocity of compressional waves in the first refraction layer

$c_{n}=$ velocity of compressional waves in the nth refraction layer

$R_{1}=$ travel time of the first reflected wave

$\mathrm{R}_{2} \mathrm{~g}$ travel time of the second reflected wave

$R_{3}=$ travel time of the third reflected wave

$R_{m}=$ travel time of the mth reflected wave

$D$ = travel time of the direct wave

$G=$ travel time of refraction arrival

$B=$ botton reflection time from the shot record

$S B=$ surface-bottom reflection time from the shot record

$\Delta W=$ topographic correction

$\Delta h=$ difference in elevation of the bottom from the mean

$H=$ depth of the ocean

$\theta \quad$ angle of incidence of $\mathrm{R}_{I}$ on bottom

$\alpha=$ angle of incidence of $G$ on bottom 


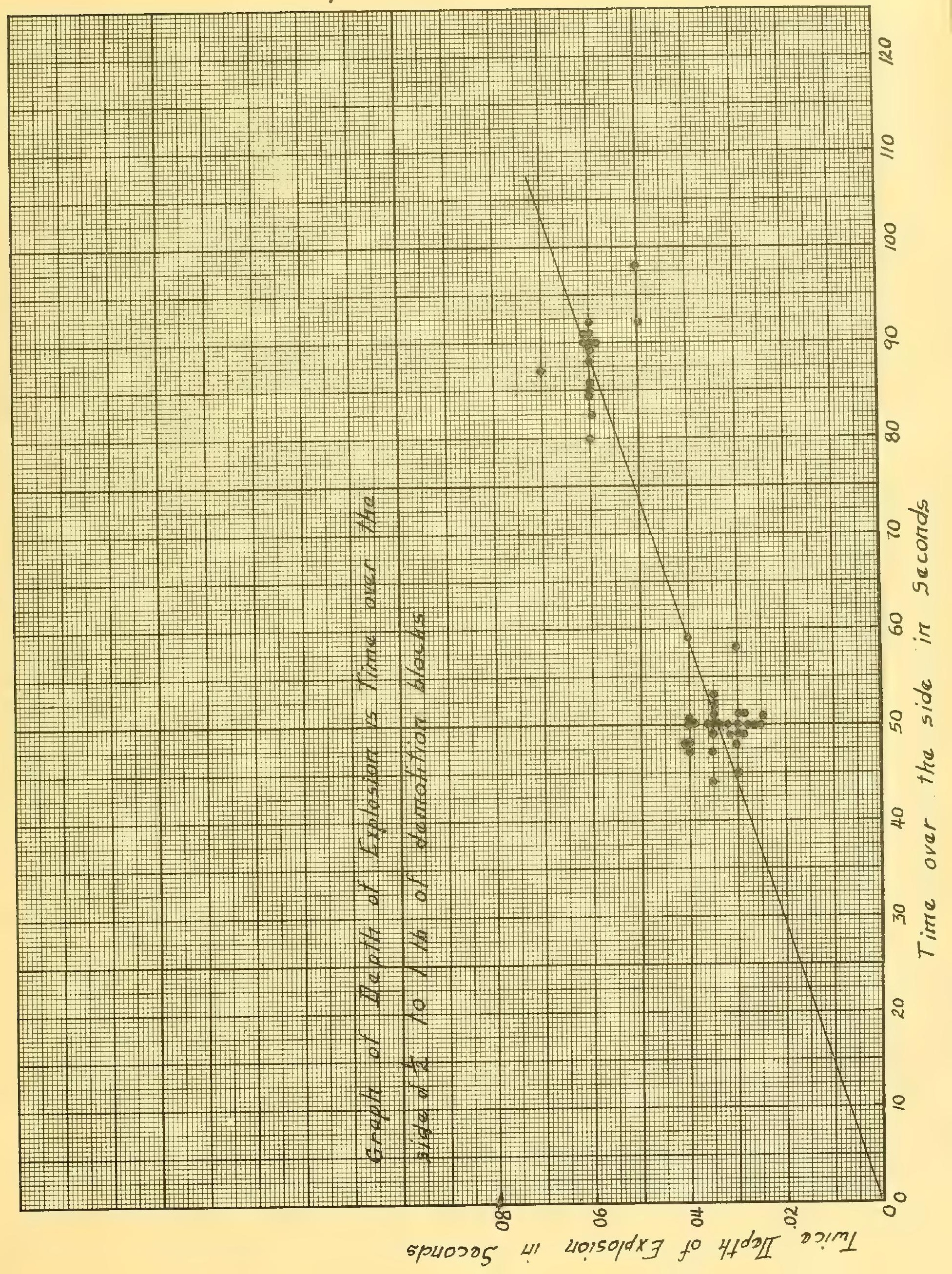




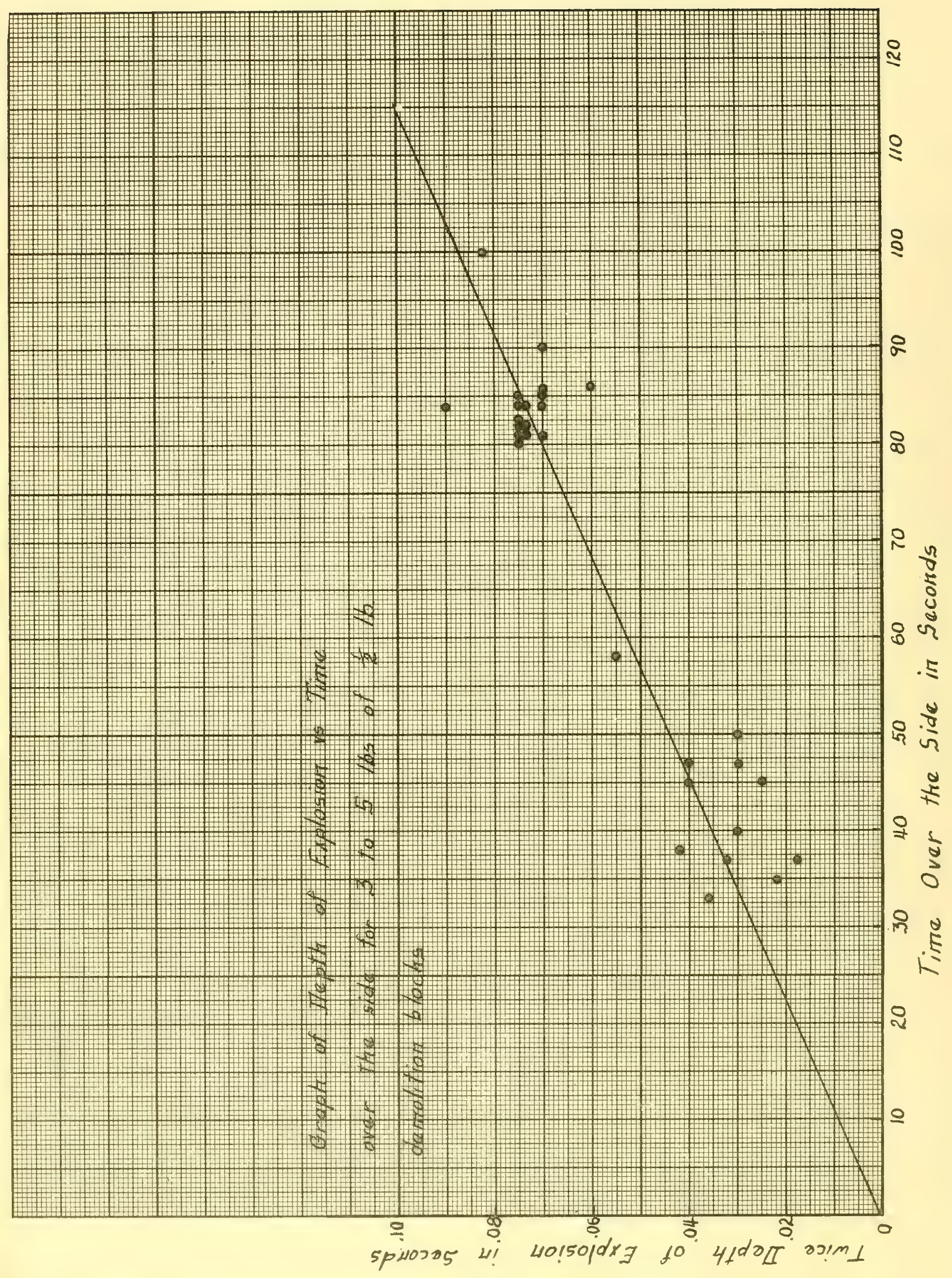




\section{Fiqure 5}

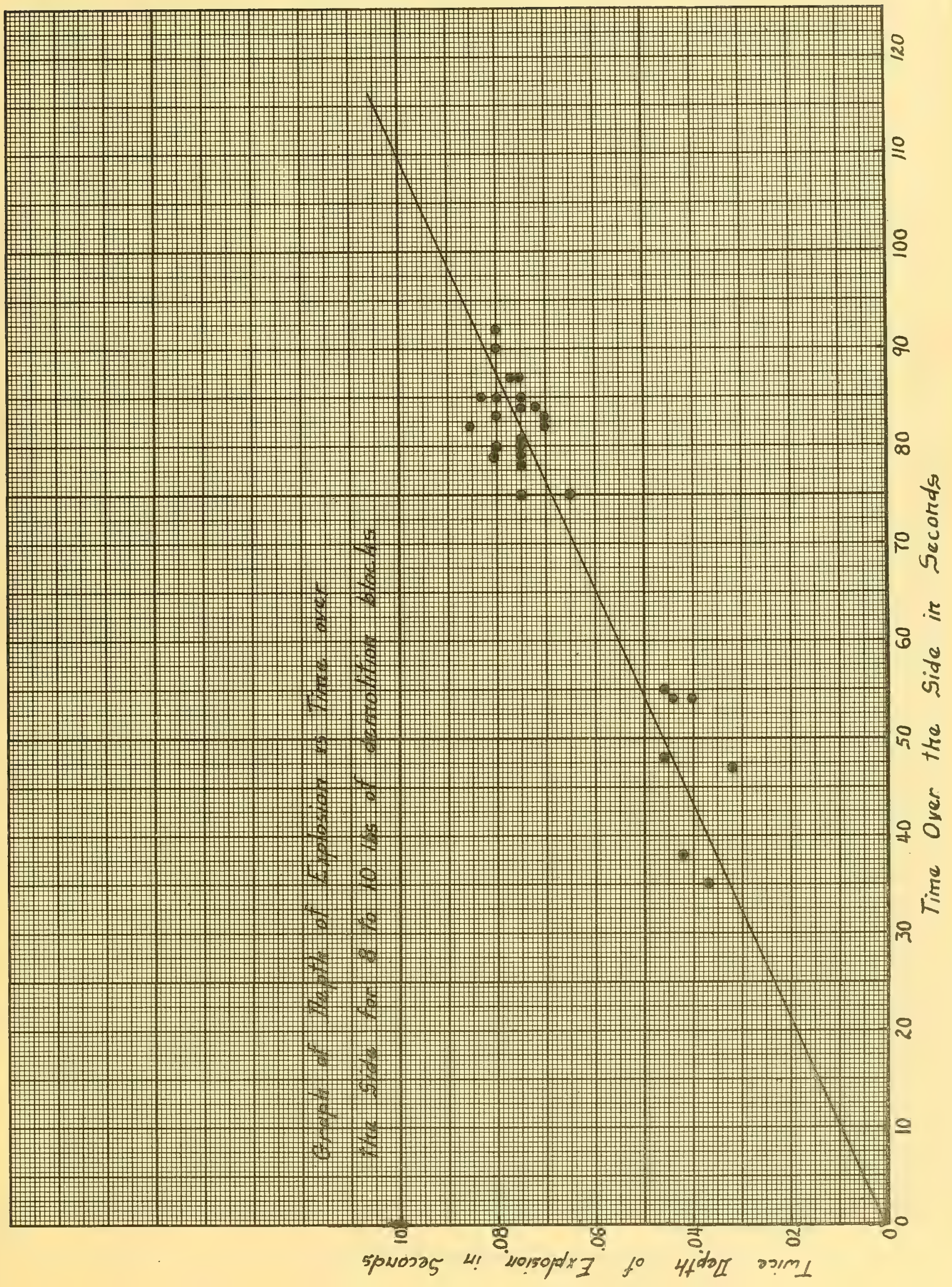




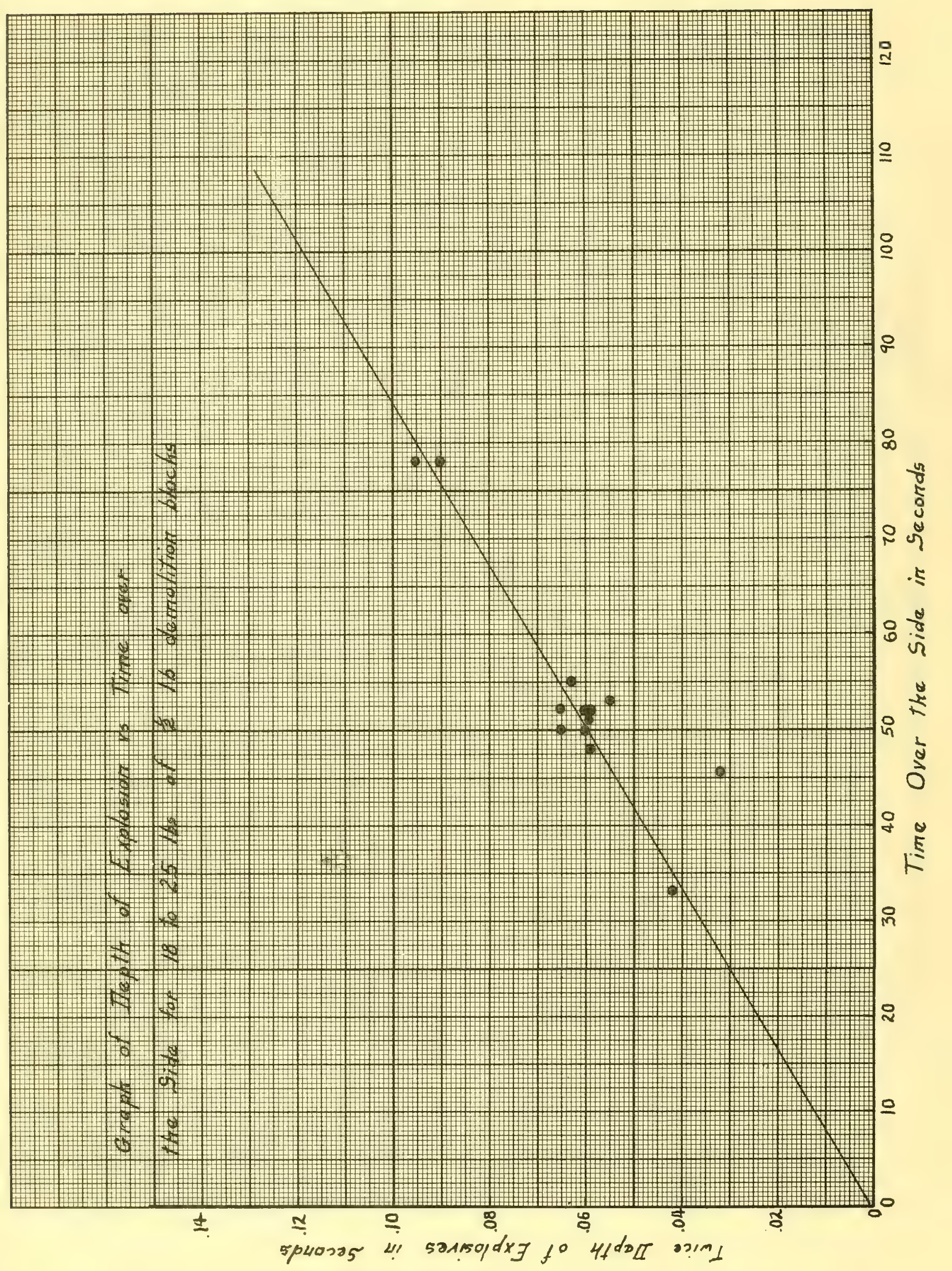




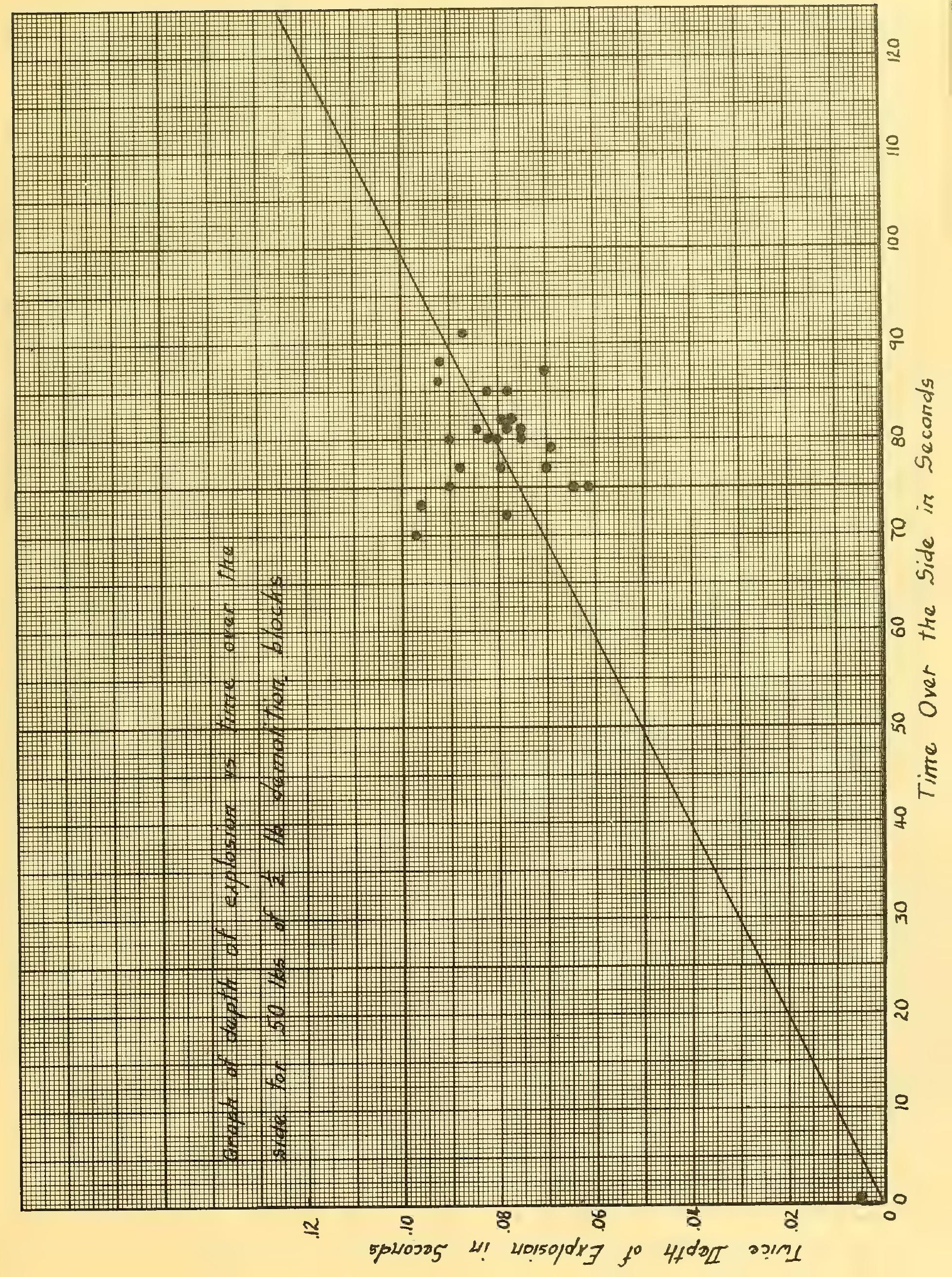




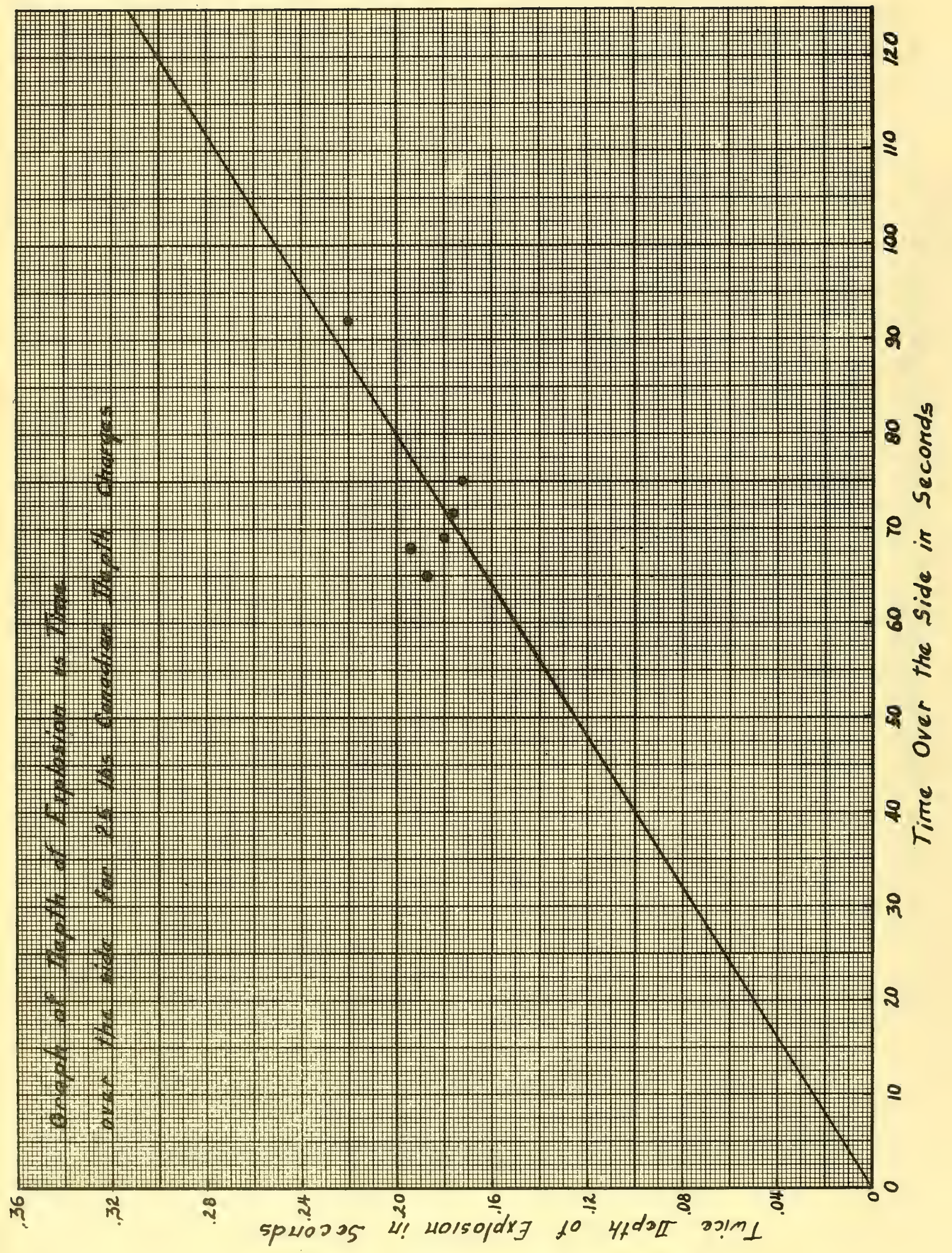




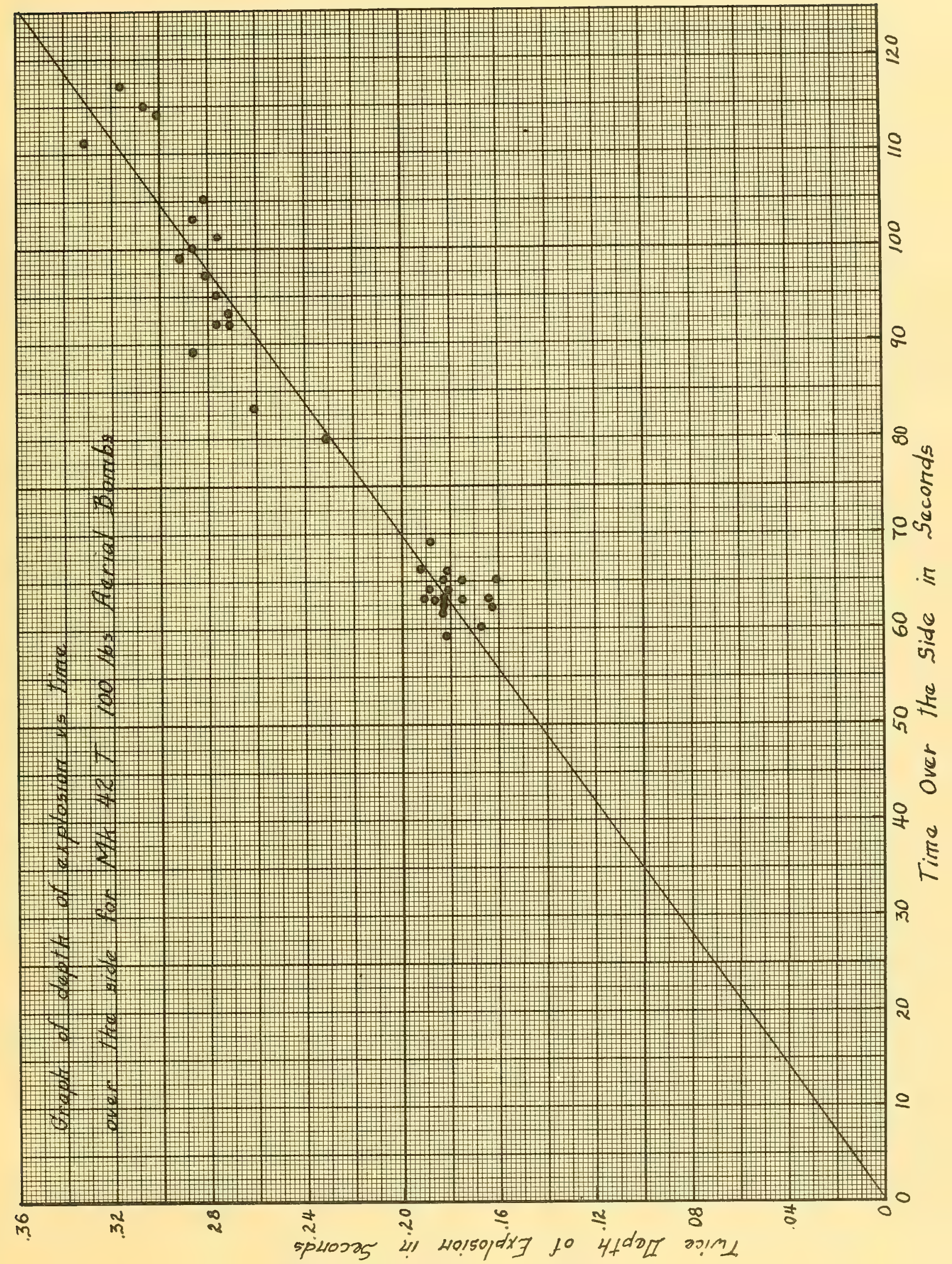




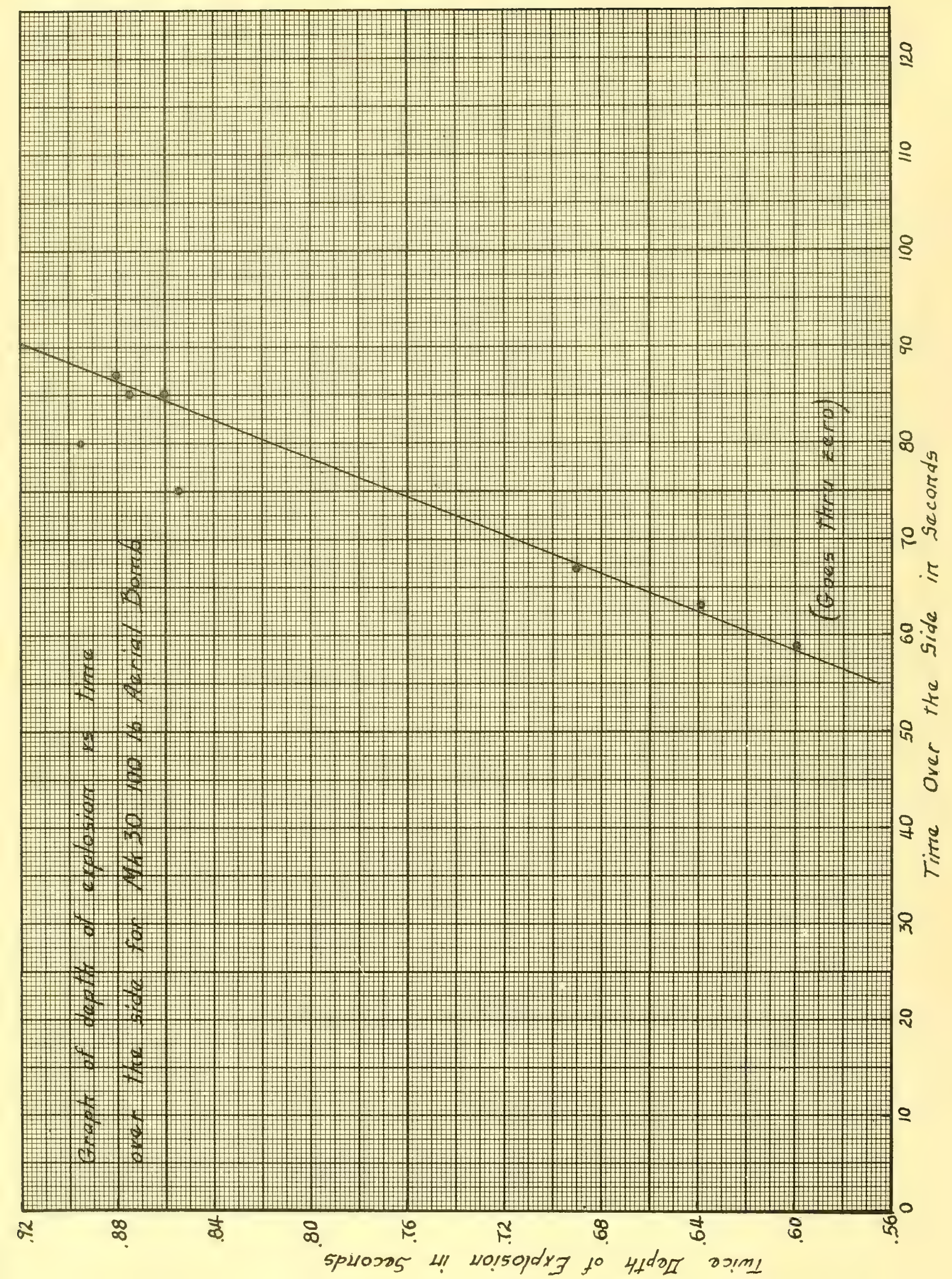




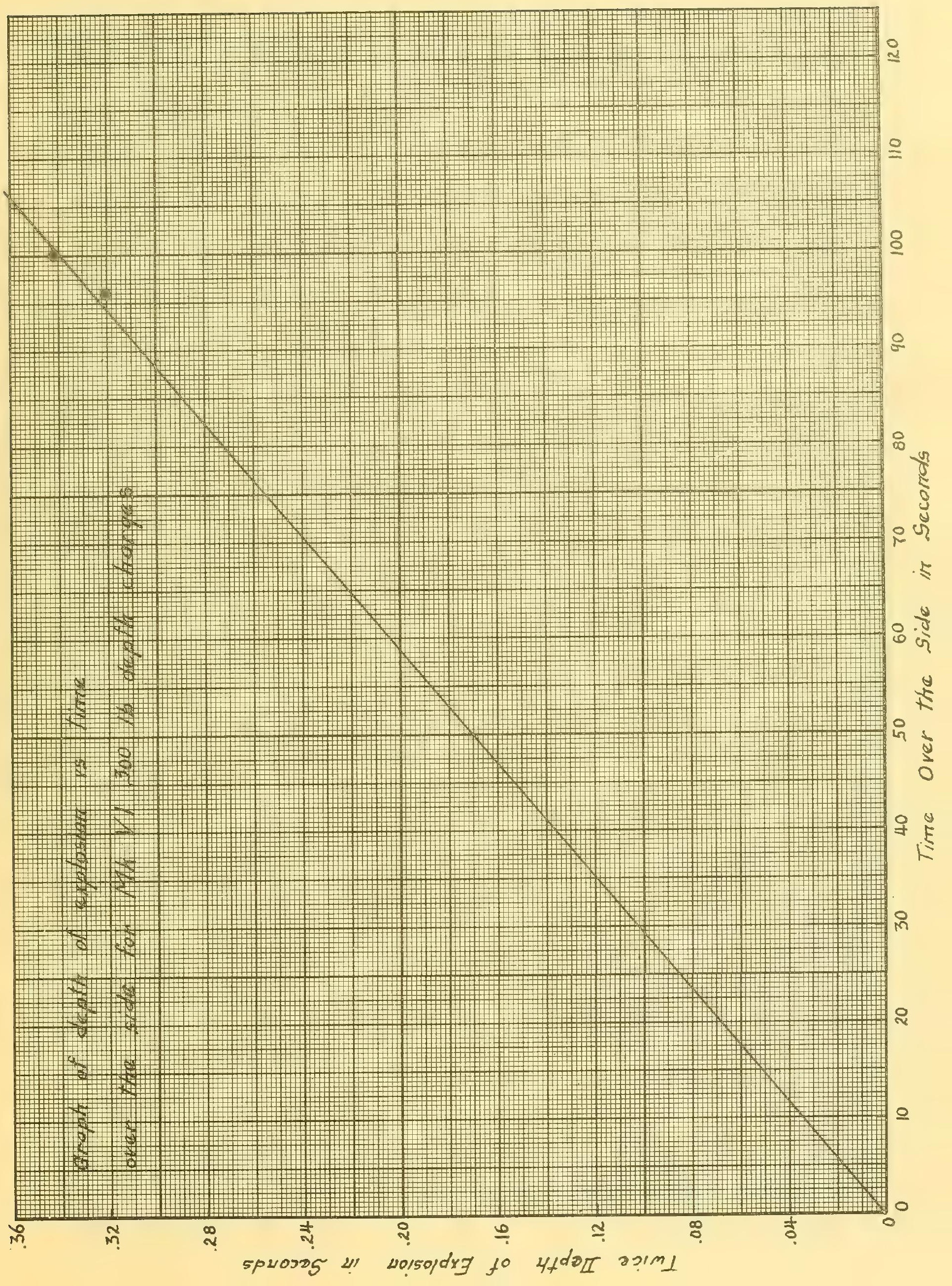




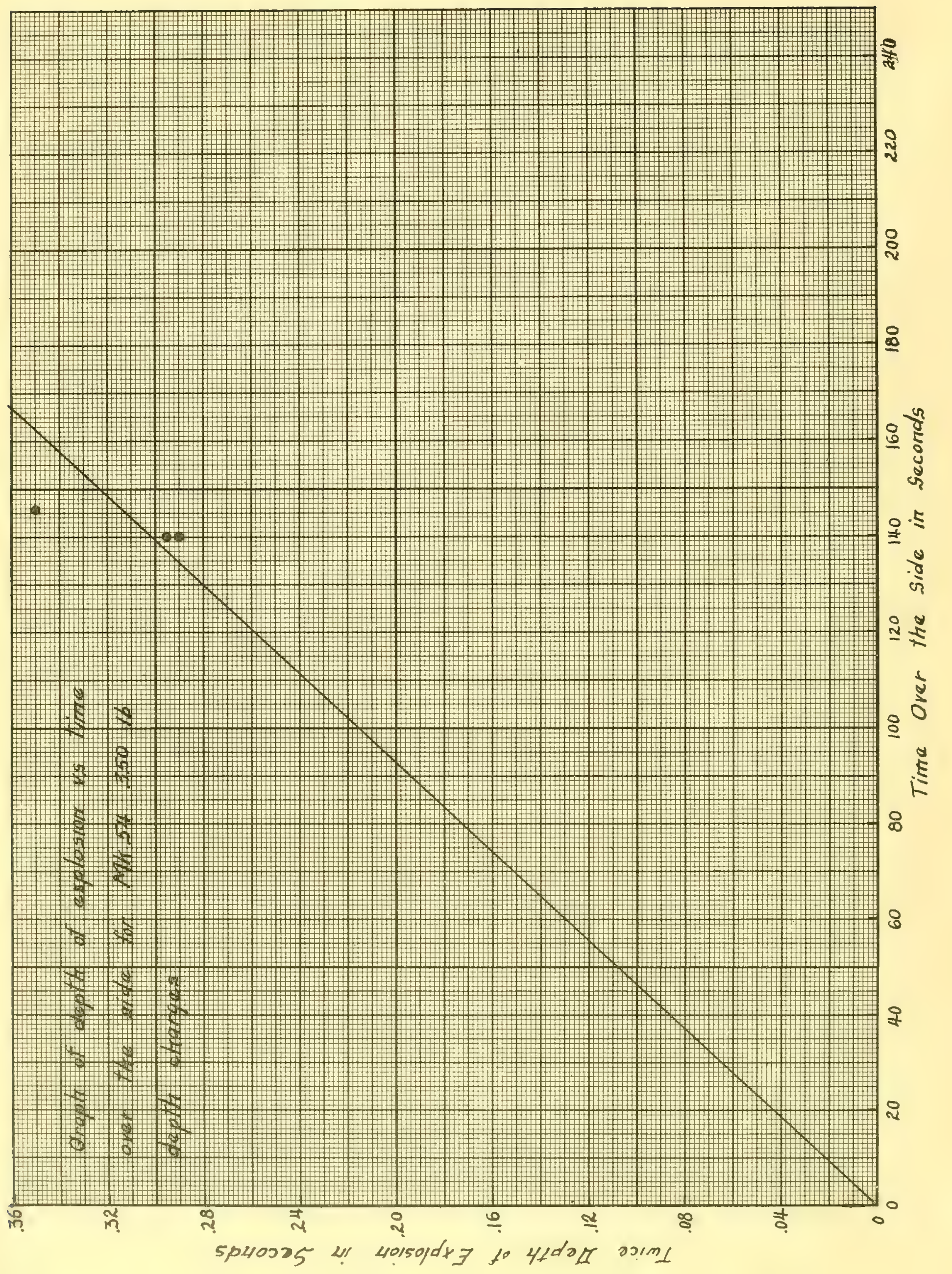




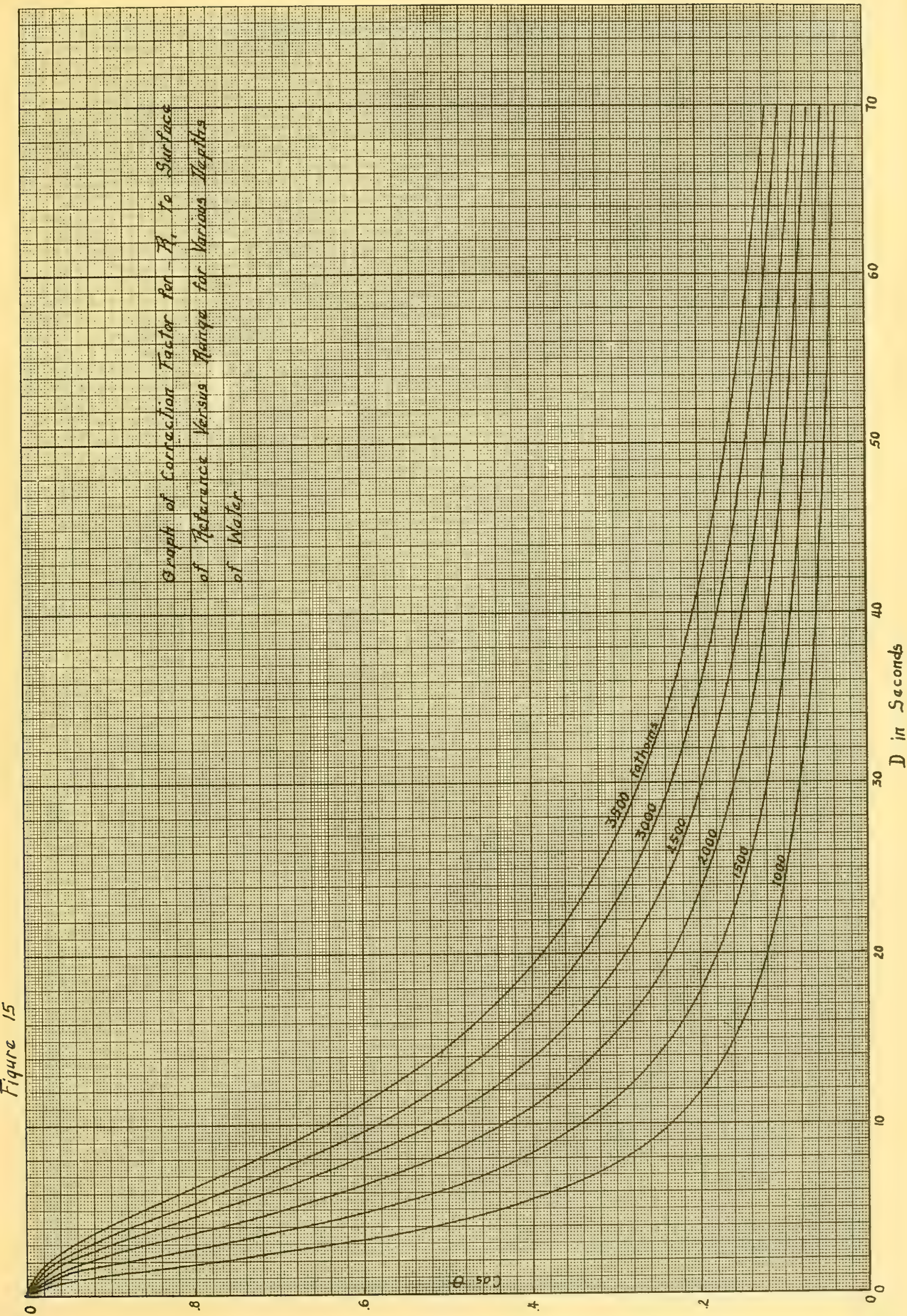



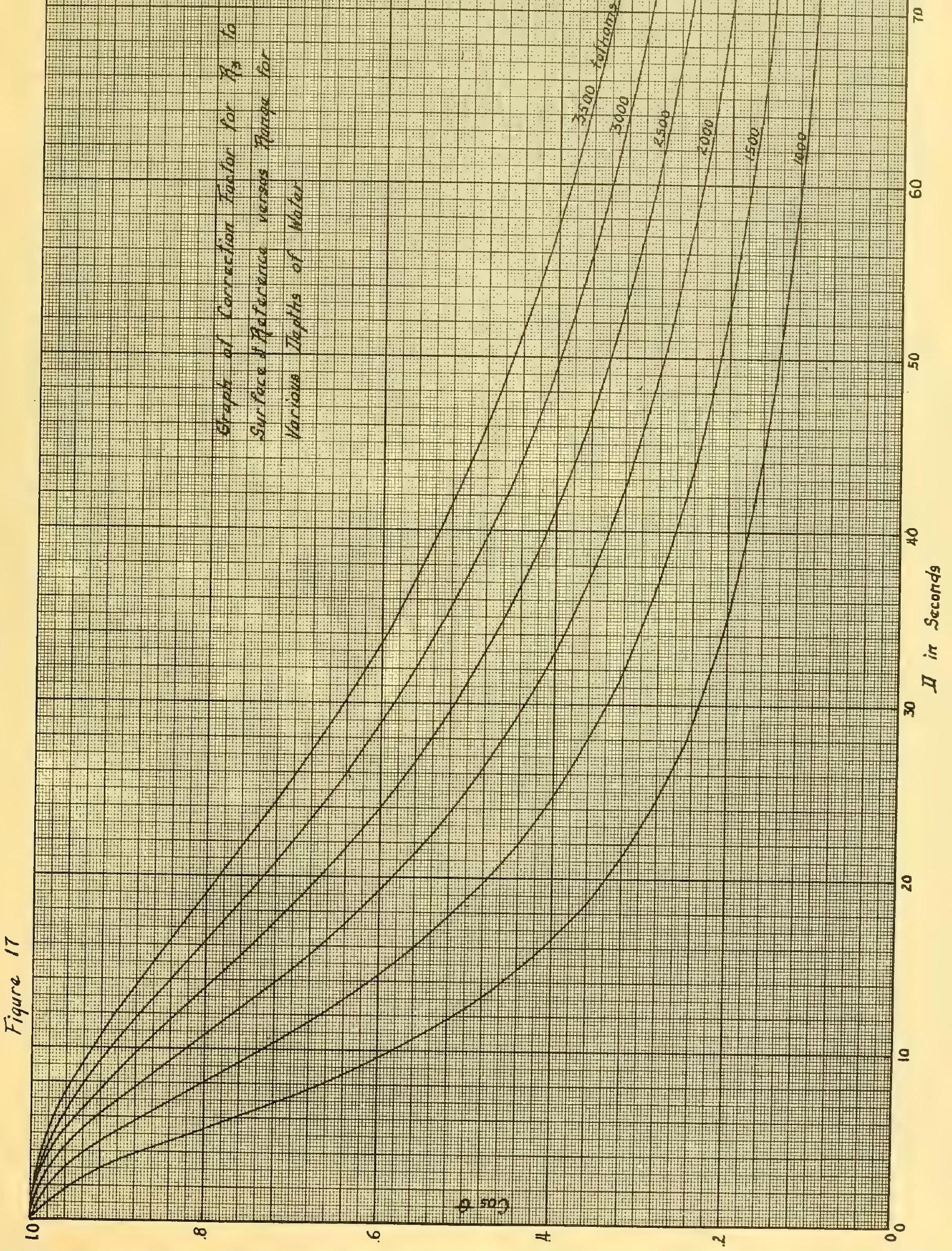


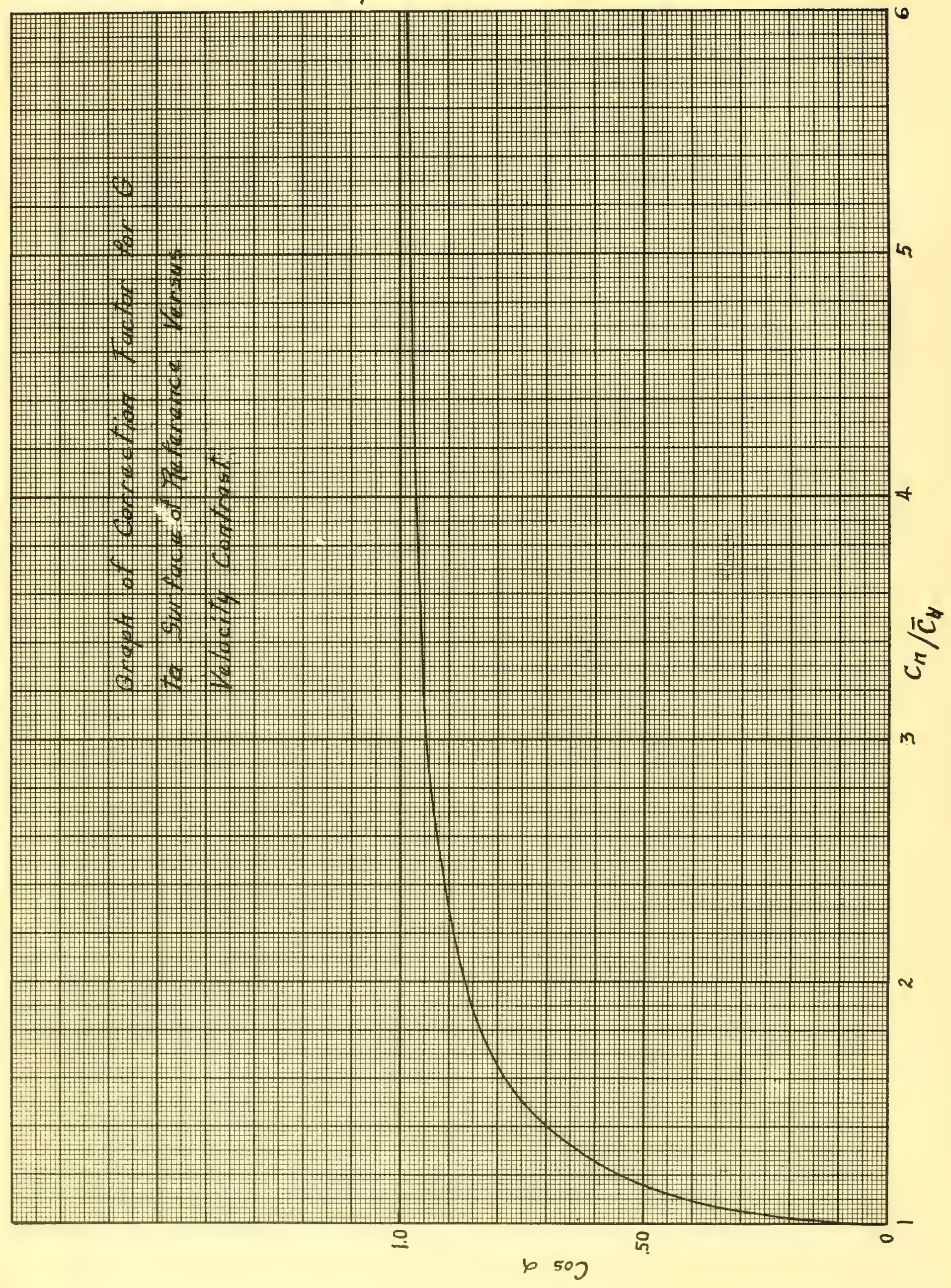




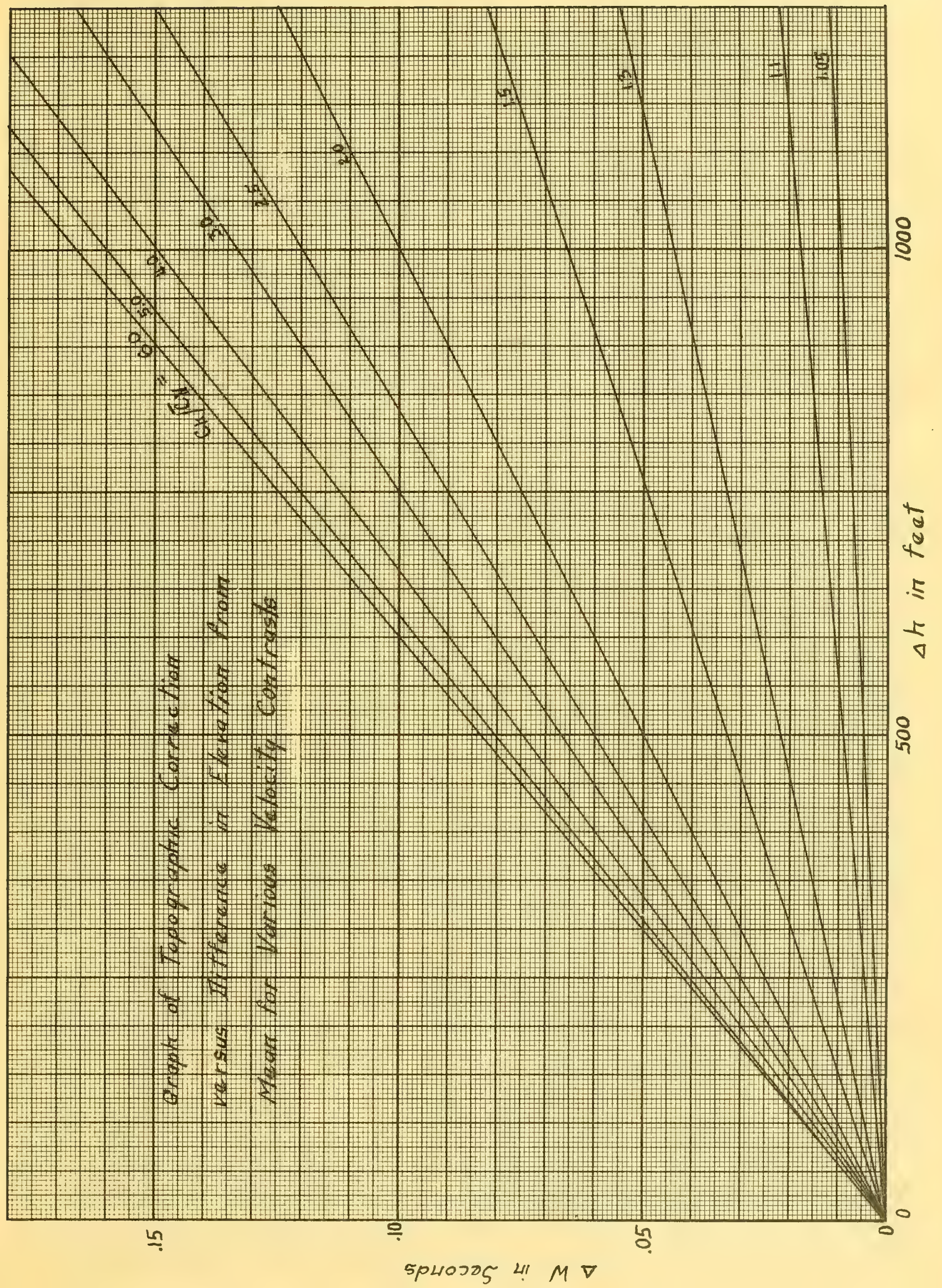




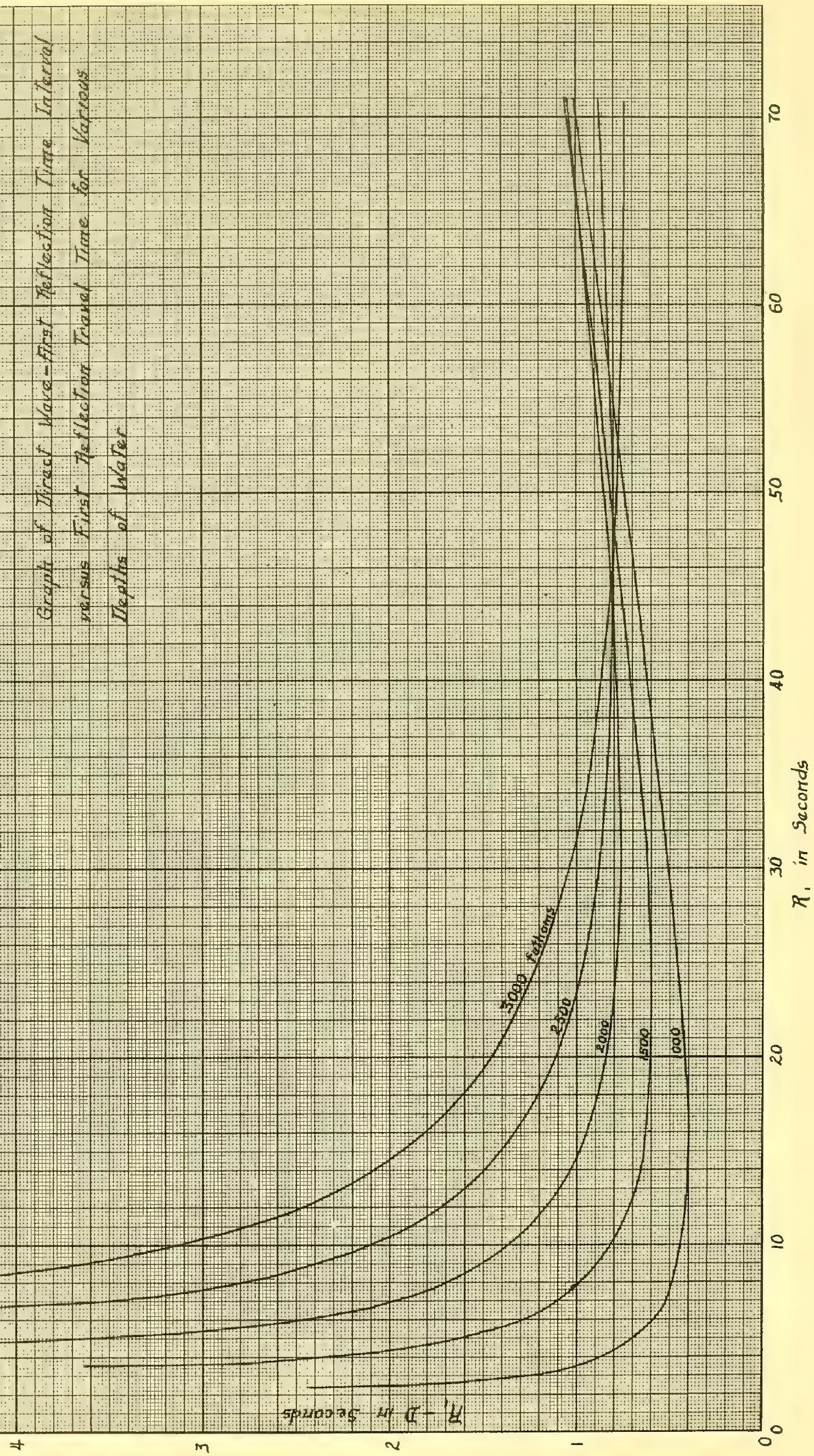





